\title{
Diagnosing the seasonal land-atmosphere correspondence over northern Australia: dependence on soil moisture state and correspondence strength definition
}

\author{
M. Decker, A. Pitman, and J. Evans \\ Climate Change Research Centre and ARC Centre of Excellence for Climate System Science, \\ University of New South Wales, Sydney, Australia \\ Correspondence to: M. Decker (m.decker@unsw.edu.au) \\ Received: 21 July 2014 - Published in Hydrol. Earth Syst. Sci. Discuss.: 19 September 2014 \\ Revised: 30 June 2015 - Accepted: 4 July 2015 - Published: 6 August 2015
}

\begin{abstract}
The similarity of the temporal variations of land and atmospheric states during the onset (September) through to the peak (February) of the wet season over northern Australia is statistically diagnosed using ensembles of offline land surface model simulations that produce a range of different background soil moisture states. We derive the temporal correspondence between variations in the soil moisture and the planetary boundary layer via a statistical measure of rank correlation. The simulated evaporative fraction and the boundary layer are shown to be strongly correlated during both SON (September-October-November) and DJF (December-January-February) despite the differing background soil moisture states between the two seasons and among the ensemble members. The sign and magnitude of the boundary layer-surface layer soil moisture association during the onset of the wet season (SON) differs from the correlation between the evaporative fraction and boundary layer from the same season, and from the correlation between the surface soil moisture and boundary layer association during DJF. The patterns and magnitude of the surface fluxboundary layer correspondence are not captured when the relationship is diagnosed using the surface layer soil moisture alone. The conflicting results arise because the surface layer soil moisture lacks strong correlation with the atmosphere during the monsoon onset because the evapotranspiration is dominated by transpiration. Our results indicate that accurately diagnosing the correspondence and therefore coupling strength in seasonally dry regions, such as northern Australia, requires root zone soil moisture to be included.
\end{abstract}

\section{Introduction}

The land surface influences the atmosphere at multiple spatial and temporal scales (Pitman, 2003; Pielke et al., 2011; Williams and Maxwell, 2011). Land-atmosphere coupling strength is the degree to which land surface anomalies (e.g., soil moisture, vegetation characteristics, temperature, snow cover) lead to changes in atmospheric states and fluxes (e.g., rainfall, cloud cover, moisture convergence) as well as how anomalies in the atmosphere affect the land surface. The influence of land surface anomalies on atmospheric anomalies (and vice versa) proceeds through a chain of non-linear processes. The strength of these processes varies spatially and temporally and depend, in part, on the background state of the system (Betts, 2004; Betts et al., 1996; Koster and Suarez, 2003; Taylor and Ellis, 2006). The chain of mechanisms between soil moisture (SM) and precipitation $(P)$ anomalies can be summarized following Santanello et al. (2011) as

$\Delta \mathrm{SM} \Rightarrow \Delta \mathrm{EF}_{\mathrm{SM}} \Rightarrow \Delta \mathrm{PBL} \Rightarrow \Delta \mathrm{EF}_{\mathrm{ATM}} \Rightarrow \Delta \mathrm{CLD} \Rightarrow \Delta P$,

where the changes in soil moisture $(\triangle \mathrm{SM})$ lead to changes in evaporative fraction $\left(\Delta \mathrm{EF}_{\mathrm{SM}}\right)$, which alters the properties of the planetary boundary layer $(\Delta \mathrm{PBL})$ including the state (temperature, humidity) and the entrainment rate. These three near-surface coupling mechanisms $\left(\Delta \mathrm{SM}, \Delta \mathrm{EF}_{\mathrm{SM}}\right.$, and $\triangle \mathrm{PBL}$ ) precede changes away from the land surface that further the change evaporative fraction $\left(\triangle \mathrm{EF}_{\mathrm{ATM}}\right)$, leading to changes in cloud development and growth $(\triangle \mathrm{CLD})$, and ultimately forcing changes in precipitation $(\Delta P)$. The chain cycles with $\Delta P$ driving $\Delta \mathrm{SM}$ to varying degrees depending on the region and season (Zhang et al., 2008). Equation (1) 
is a conceptualization of complex and non-linear processes, such that the sign of the $\triangle \mathrm{CLD}$ response to a $\triangle \mathrm{SM}$ forcing can vary (Westra et al., 2012; Gentine et al., 2013b). Equation (1) is a simplification of the short (less than a day) timescale coupling mechanisms and neglects large-scale circulation and moisture feedbacks (Lee et al., 2012; Lintner and Neelin, 2009; Lintner et al., 2013). Additional feedbacks that operate on short timescales not shown in Eq. (1), such as $\Delta \mathrm{EF}_{\mathrm{SM}}$ or $\triangle \mathrm{EF}_{\mathrm{ATM}}$ leading to $\Delta \mathrm{SM}$, may also be important (Seneviratne et al., 2010; Meng et al., 2014a, b). Despite simplifications, Eq. (1) highlights the primary control SM exerts on EF (evaporative fraction) as compared to secondary factors such as entrainment (Gentine et al., 2011). In a convective regime, $\triangle \mathrm{SM}$ initiates a series of events that first alter the atmosphere $(\triangle \mathrm{PBL})$ prior to changing $P$. The series of events $\Delta \mathrm{SM}-\triangle \mathrm{PBL}$ comprises the terrestrial portion of the coupling mechanisms and is the focus of this study. The statistical relationship between model-simulated $\Delta \mathrm{SM}$ or $\Delta \mathrm{EF}$ and the observed $\triangle \mathrm{PBL}$ is examined here. The $\triangle \mathrm{SM}$ through $\triangle \mathrm{PBL}$ sequence is a necessary, but not sufficient, set of processes that determine how $P$ responds to changes in SM. Therefore, by demonstrating the limitations of various statistical metrics in capturing the relationships between $\triangle \mathrm{SM}$, $\triangle \mathrm{EF}$, and $\triangle \mathrm{PBL}$, this study highlights the periods and conditions that coupling can be diagnosed using the aforementioned diagnostic metrics.

The sensitivity of atmospheric processes to $\Delta \mathrm{SM}$ has been quantified with observations (Koster et al., 2003; Taylor and Ellis, 2006) and multiple model experiments (Dirmeyer et al., 2006; Guo et al., 2006; Hirsch et al., 2014; Koster et al., 2000, 2006, 2011; Lee et al., 2012). Ferguson et al. (2012) combined multiple sources of reanalysis data with LCL (lifting condensation level) and SM observations to examine the relationship between early morning surface layer SM $\left(\mathrm{SM}_{1}\right)$ and both the LCL and the EF in the afternoon during the convective season. The relationship was quantified using the Kendall $\tau$ coefficient $(K \tau)$, a non-parametric rank correlation coefficient that measures the association between two time series. Ferguson et al. (2012) found strong coupling $(K \tau)$ between $\mathrm{SM}_{1}-\mathrm{EF}$, EF-LCL, and $\mathrm{SM}_{1}-\mathrm{LCL}$ over many regions including monsoon regions such as northern Australia. These three coupling mechanisms span the first three components in Eq. (1) ( $\left.\Delta \mathrm{SM}, \Delta \mathrm{EF}_{\mathrm{SM}}, \Delta \mathrm{PBL}\right)$. While these represent only part of the processes involved in landatmosphere coupling, they comprise a fundamental pathway by which SM anomalies drive an atmospheric response.

Several regional analyses have investigated the importance of land-atmosphere coupling in northern Australia (Evans et al., 2011). Koster et al. (2000) showed land-atmosphere coupling increased the variance of $P$ in both northern and eastern Australia. In agreement, Ferguson et al. (2012) found high correlations in $\mathrm{SM}_{1}-\mathrm{EF}, \mathrm{EF}-\mathrm{LCL}$, and $\mathrm{SM}_{1}-\mathrm{LCL}$ during the convective (monsoon) season over the northern savannas. These studies were limited in scope and did not explicitly explore how the coupling behaves during periods with different background climate states. Therefore, it is important to evaluate whether the methods used to characterize land-atmosphere behavior are valid during alternate periods with varying background states.

To examine statistical measures of land-atmosphere coupling strength we explore the correspondence between the temporal variations in land-surface-model-derived soil moisture and water flux estimates with the observation-based estimates of the variations in the boundary layer state. The relationship between $\mathrm{EF}$ and shallow cumuli have been demonstrated by Gentine et al. (2013a); however, here we examine the temporal co-evolution of SM as it relates to the estimated LCL height during the onset through to the peak of the monsoon season. Significant statistical association between soil moisture or surface fluxes and the atmosphere provides a necessary but not sufficient condition to demonstrate significant land-atmosphere coupling. The lack of landatmosphere feedbacks in offline simulations means we cannot assess cause and effect, but by examining the statistical correspondence we can determine if the co-evolution of the simulated states (SM and EF) are consistent with observed LCL.

The statistical association is defined here such that the land surface processes in Eq. (1) $\left(\Delta \mathrm{SM}, \Delta \mathrm{EF}_{\mathrm{SM}}\right)$ are simulated and evaluated in relation to the observationally estimated $\triangle \mathrm{PBL}$. The dynamic progression represented in Eq. (1) is simulated for $\triangle \mathrm{SM}$ and $\Delta \mathrm{EF}_{\mathrm{SM}}$ only. The physical mechanisms that drive $\triangle \mathrm{PBL}$ from $\triangle \mathrm{SM}$ and $\triangle \mathrm{EF}$ are not simulated, while the sequence of events in the atmosphere $\left(\Delta \mathrm{EF}_{\mathrm{ATM}}, \Delta \mathrm{CLD}\right.$ and $\left.\Delta P\right)$ are neglected. This terrestrial-derived statistical association captures how a model-simulated $\triangle \mathrm{SM}$ relates to state changes in the afternoon mixed layer ( $\triangle \mathrm{PBL}$ ) by assuming that $\triangle \mathrm{PBL}$ can be characterized using near-surface atmospheric states. Strong association as defined here is a necessary but not sufficient prerequisite for strong $\Delta \mathrm{SM}-\Delta \mathrm{PBL}$ or $\Delta \mathrm{SM}-\Delta P$ coupling because the full chain of events is not simulated. An ensemble of offline simulations using two model configurations, one of which neglects groundwater and therefore contains greatly reduced deep soil moisture, are driven using four forcing data sets. The simulations provide estimates of $\mathrm{SM}_{1}$ in addition to $\mathrm{SM}$ over the root zone $\left(\mathrm{SM}_{\mathrm{rz}}\right)$, total $\mathrm{ET}$ and the ET components. Afternoon (14:00 LT) LCL is derived using the near-surface atmospheric variables from the forcing data sets, and the sensitivity of the ensemble median $K \tau$ is examined for the onset and peak of the monsoon season.

We focus on northern Australia to examine whether the relationship between soil moisture and the boundary layer can be diagnosed from $\mathrm{SM}_{1}$ in regions with a pronounced dry season, given the influence of groundwater on transpiration and deep SM variability (Decker et al., 2013). Northern Australia has a pronounced May to September dry season and a monsoon-driven wet season from November through February (Fig. 1). The monsoonal climate allows us to examine the $\mathrm{SM}_{1}-\mathrm{LCL}$ association as defined in Ferguson et al. (2012) 


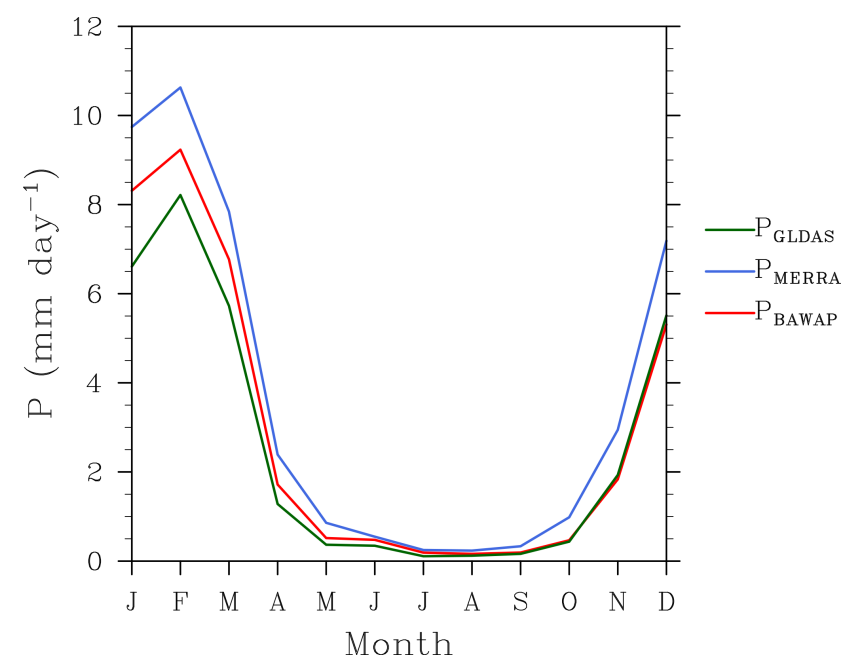

Figure 1. Observations of the $\left(18-11^{\circ} \mathrm{S}, 120-150^{\circ} \mathrm{E}\right)$ domainaveraged mean annual cycle of precipitation $\left(P\right.$ in mm day $\left.^{-1}\right)$.

in sharply contrasting seasons (Fig. 1) that exhibit contrasting background soil moisture states. By examining the differences between correspondence during the onset (defined here as SON, September-October-November, to coincide with the initial increase in rainfall) of the wet season when soil moisture will be low and then through to the peak (defined as DJF, December-January-February, to coincide with the precipitation maximum) of the wet season, we aim to determine the reliability of diagnosing the terrestrial and near-surface stages of land-atmosphere correspondence using $K \tau$ derived from $\mathrm{SM}_{1}$ and $\mathrm{LCL}$ during periods where total ET fluxes are dominated by either soil evaporation or transpiration.

This manuscript is organized as follows. The model simulations, the $\mathrm{SM}_{1}$ and ET observations used for model evaluation, and the near-surface atmospheric data sets are summarized in Sect. 2. Section 3 outlines the statistical measure used to define the association between the different states, the derivation of LCL from the atmospheric data, and the model experiments used to estimate the evaporative fraction and soil moisture. The Results section consists of the $\mathrm{SM}_{1}$ LCL- and EF-LCL-based association strength; the impacts of defining association strength with $\mathrm{SM}_{\mathrm{rrz}}$ (the root zone SM) are presented in Sect. 4. The results are explained in terms of the governing physical processes and previous research in Sect. 5.

\section{Model simulations and data}

\subsection{Near-surface atmospheric and forcing data}

The LCL (see Sect. 3.2) over the entire study region is computed from combinations of near-surface atmospheric data using two reanalysis products. The LCL is also calculated at the two flux sites using the tower observations. The model simulations (see Sect. 2.2) are driven using a combination of atmospheric states and fluxes from reanalysis products, a gauge-based daily precipitation data set, and a 3-hourly satellite-based precipitation product. We follow Decker et al. (2014) and utilize four forcing data sets to drive model simulations.

The two gridded sources of temperature, humidity, wind speed, pressure, and radiative fluxes are the Global Land Data Assimilation System (GLDAS; http://disc.sci.gsfc.nasa. gov/hydrology/data-holdings; Rodell et al., 2004) and the Modern-Era Retrospective Analysis for Research and Applications (MERRA) product (Bosilovich et al., 2008). These two data sets are utilized due to the high spatial resolution of GLDAS $\left(0.25^{\circ}\right)$ and high temporal resolution of MERRA (hourly). Two forcing data sets are comprised of the uncorrected GLDAS and MERRA data interpolated to a common $0.25^{\circ} \times 0.25^{\circ}$ grid. In addition, two precipitationcorrected data sets developed in Decker et al. (2014) are used. The uncorrected atmospheric states and radiative fluxes from MERRA are combined with $P$ corrected via two algorithms. First, MERRA is corrected using the Australian Water Availability Project (AWAP) daily gridded precipitation data (Jones et al., 2009) to remove the monthly biases (labeled MERRA.B). Second, the MERRA precipitation is replaced with precipitation derived from disaggregating the daily AWAP data with the 3-hourly Tropical Rainfall Measuring Mission (TRMM) 3B42 (Huffman et al., 2007) data (labeled MERRA.BT). These two corrected data sets have identical monthly mean precipitation but different distributions of submonthly precipitation.

\subsection{Simulated estimates of soil moisture and evaporative fraction}

We use the Community Land Model version 4 (CLM4; Oleson et al., 2010) to simulate the states and fluxes of water and energy using configurations documented in Decker et al. $(2013,2014)$. The land surface model simulations and reanalysis products allow for the relationships within the terrestrial leg (SM-PBL in Eq. 1) to be diagnosed without fully simulating the land surface-atmosphere dynamics and feedbacks. A detailed description of the groundwater configurations and modifications are given in Decker et al. (2014).

The suite of simulations is utilized to address forcing data and model configuration uncertainties in addition to exploring a large soil moisture state space. Two different configurations of CLM4 are used. The first consists of the default CLM4 (referred to as CTRL). The second (referred to as DRY) uses a modified CLM4 that replaces the two-way soil moisture coupling between the soil column and the aquifer with a free drainage bottom boundary condition. The modifications significantly reduce the soil moisture at depths below several centimeters and the ET flux during periods of low rainfall while not imparting large differences on the changes in total column water (Decker et al., 2014). The two model 
configurations thus enable the coupling between the atmosphere and the land surface to be examined under two differing background soil moisture states.

The CLM4 evapotranspiration is computed as the sum of the soil evaporation, the canopy evaporation and the transpiration. Transpiration is determined from the rate of photosynthesis and is, in part, a function of SM. The dependence on SM is determined by the soil water potential in each soil layer, the root distribution (prescribed by plant functional type, PFT), and the PFT dependence on water stress. The spatial distribution and phenology of PFTs are specified and identical across all simulations. The C3 grass PFT sets approximately $99 \%$ of the roots within $1 \mathrm{~m}$ of the surface, while approximately $90 \%$ of the roots are within this depth for the broadleaf evergreen forest PFT.

The experiment design follows the simulations outlined in Decker et al. (2014) that have been shown to be in good agreement with observations over parts of Australia. One control (CTRL) simulation and one dry simulation are equilibrated for the period 1948-1979 using the corrected NCEP/NCAR data (Qian et al., 2006) after interpolating to the same $0.25^{\circ} \times 0.25^{\circ}$ grid as the other forcing data sets. The CTRL and DRY simulations ending in 1979 provide initial conditions for the four CTRL and four DRY simulations from 1979 to 2007. The model evaluation period spans the 5 years coincident with the SM and ET data from 2003 to 2007. The associations are computed using the period 1990-2008. Both the CTRL and the DRY simulations are forced with the four forcing data sets (see Sect. 2.1): GLDAS, MERRA, MERRA.B, and MERRA.BT, generating a total of eight model simulations. The SM (from all model layers) and turbulent energy fluxes are output at 3-hourly intervals (coincident with the temporal resolution of the GLDAS forcing), while the remaining CLM4 output is saved as monthly means.

\subsection{Validation data: soil moisture and evapotranspiration}

The spatiotemporal behavior of the simulated surface soil moisture $\left(\mathrm{SM}_{1}\right)$ and evapotranspiration (ET) are validated against gridded observationally based estimates. $\mathrm{SM}_{1}$ is evaluated against the daily Advanced Microwave Scanning Radiometer - Earth Observing System (AMSR-E) L3 surface SM product. The data are derived from passive microwave measurements and available for the period 20022011 (Njoku et al., 2003). AMSR-E-based SM compares favorably with in situ measurements over Australia (Draper et al., 2009) and exhibits spatiotemporal variability consistent with land model simulations (Liu et al., 2009). To simplify the comparison with the simulated SM, the first model layer ( $\sim 0.7 \mathrm{~cm}$ deep) $\mathrm{SM}$ is assumed comparable to $\mathrm{SM}$ from AMSR-E despite the uncertain effective measurement depth (approximately $1 \mathrm{~cm}$ ) that varies with SM.
The simulated evapotranspiration is evaluated against three ET products. Multiple ET data sets based on different methodologies are included due to the uncertainty associated with deriving gridded moisture flux data (Jiménez et al., 2011). The Global Land Evaporation Amsterdam Methodology (GLEAM; Miralles et al., 2011a, b), the modeltree ensemble-based data set from MPI-Jena (J2010 hereafter) (Jung et al., 2010), and the Moderate Resolution Imaging Spectrometer (MODIS) MOD16 data set (Mu et al., 2007, 2011) are used to estimate the observed mean seasonal ET fluxes. The observed ET is estimated using the arithmetic mean of the three data sets after the GLEAM and MOD16 data are aggregated to the coarse resolution $\left(0.5^{\circ} \times 0.5^{\circ}\right)$ of the $\mathrm{J} 2010$ data. The simulations are subsequently compared to the mean observed ET separately for the wet season (December-February) and the end of the dry season (September-November).

In addition to the gridded SM and ET data sets, the model is evaluated against observations from two flux tower sites included in the OZ Flux network (ozflux.org.au). The Adelaide River site (Beringer, 2013a) spans November 2007 through May 2009 and is located at $13.08^{\circ} \mathrm{S}, 131.12^{\circ} \mathrm{E}$. The Howard Springs site (Beringer, 2013b) spans from 2001 to present and is located at $12.48^{\circ} \mathrm{S}, 131.15^{\circ} \mathrm{E}$. Both sites provide air temperature, water vapor, surface pressure, radiation, turbulent fluxes (including ET), and soil moisture measurements at $30 \mathrm{~min}$ intervals. The level 3 (L3) quality controlled data were utilized in this study. Adelaide River provides SM data at $5 \mathrm{~cm}$ depth while Howard Springs provides $\mathrm{SM}$ at a depth from $10 \mathrm{~cm}$. The simulations are validated against the observed ET and SM at these two locations.

\section{Methods}

\subsection{Kendall $\tau$}

We evaluate the relationships between variables involved in land-atmosphere coupling processes using $K \tau$, a nonparametric, rank correlation statistic (Press et al., 1992). Following Ferguson et al. (2012), $K \tau$ is used to indicate the correspondence between two states important to landatmosphere coupling. $K \tau$ does not assume linearity between the variables being compared and tests for statistical significance. $K \tau$ ranges from -1 to 1 (positive values indicate the temporal variations are synchronized), with statistical significance depending on the sample size (approximately 0.12 for the simulation-based results in this study). $K \tau$ is defined as

$K_{\tau}=\frac{N_{\mathrm{o}}-N_{\mathrm{d}}}{0.5 n(n-1)}$,

where $N_{\mathrm{o}}$ is the number of ordinate pairs, $N_{\mathrm{d}}$ is the number of disordinate pairs, and $n$ is the number of observations. Ordinate pairs are pairs of numbers for which the change between them have the same sign, i.e., both are either positive 
or negative. The strong seasonal cycle in northern Australia (Figs. 2, 3) necessitates that the seasonality be removed from the data or it will likely control the statistical relationship. The least squares linear trend is removed from the data by calculating the trend over each season individually. The data are detrended instead of removing the monthly mean annual cycle to ensure we do not create discontinuities within a season. Removing the mean annual cycle could possibly subtract very different mean values from points that are continuous in time, causing artificial discontinuities between the data from the last day of a month and the first day of the subsequent month. Detrending the data over a season ensures the methods do not introduce artificial discontinuities between months within a given season. The spatially distributed $K \tau$ is calculated between the seasonally detrended 3-hourly modeled $\mathrm{SM}_{1}$ during the morning and the estimated 3-hourly LCL from the afternoon at each grid cell for each month during both the wet and dry seasons. $K \tau$ is additionally derived with detrended data at two flux tower sites using measurements of SM and LCL estimated from the tower data. The morning $\mathrm{SM}_{1}$ is utilized because $\mathrm{SM}$ will be highest in the morning prior to decreasing during the day due to ET. The local time of SM and LCL varies because the simulations and forcing data utilize Greenwich Mean Time (GMT). The distributed $K \tau$ is found separately for each of the eight simulated (see Sect. 2.2) estimates of $\mathrm{SM}_{1}$ and the four estimates of LCL (Sect. 3.2), generating a total of 32 estimates of $K \tau$ for each month in both the wet and dry seasons. The median $K \tau$ is found separately for the wet and dry seasons for the two different model configurations (Sect. 3.3) to give the final estimation of the correspondence. The association is also diagnosed using $K \tau$ between the model-simulated afternoon evaporative fraction and the afternoon LCL. A second definition of association is found by calculating $K \tau$ between the morning time root zone $\mathrm{SM}\left(\mathrm{SM}_{\mathrm{rz}}\right)$ and the afternoon $\mathrm{LCL}$ $\left(\mathrm{SM}_{\mathrm{rz}}-\mathrm{LCL}\right) . \mathrm{SM}_{\mathrm{rz}}$ is defined as the vertically averaged $\mathrm{SM}$ from the surface to a depth of $1 \mathrm{~m}$.

The physical meaning of a negative SM-LCL $K \tau$ association is as follows. A high value of SM will cause a larger ET flux, moistening the lower atmosphere, causing a lower LCL. Thus, we hypothesize that in regions where the land and atmosphere are coupled the SM-LCL $K \tau$ should be negative. If SM has no association with LCL, then $K \tau$ is expected to be statistically insignificant. Similarly, if ET is negatively associated with LCL $(K \tau<0)$, it means that high ET may be moistening the lower atmosphere again, leading to a lower LCL.

\subsection{Calculation of lifting condensation level}

The state of the convective atmosphere is evaluated using the LCL, defined as the height (in pressure) at which a parcel reaches saturation when ascending adiabatically from the surface. While a lower LCL is favorable to convection, it is not a sufficient constraint to guarantee it. For convection to occur a parcel must reach the level of free convection (LFC), which may not occur even if a parcel reaches the LCL. The height (in pressure) of the LCL is derived using only nearsurface variables under the assumption that the boundary layer is well developed and therefore well mixed. Estimating the LCL from near-surface variables provides heights comparable to direct observations (Ferguson and Wood, 2009). Under these assumptions, the pressure at the LCL is given by

$\mathrm{LCL}=P_{\text {srf }}-P_{\text {srf }}\left(\frac{T_{\text {air }}}{T_{\text {dew }}}\right)^{\frac{-c_{\mathrm{p}}}{R}}$,

where $P_{\text {srf }}$ is the surface pressure $(\mathrm{Pa}), T_{\text {air }}$ is the nearsurface air temperature $(\mathrm{K}), T_{\mathrm{dew}}$ is the near-surface dew point temperature $(\mathrm{K}), R$ is the specific gas constant of dry air $\left(\mathrm{J} \mathrm{K}^{-1} \mathrm{~kg}^{-1}\right)$, and $c_{\mathrm{p}}$ is the specific heat of dry air at constant pressure $\left(\mathrm{J} \mathrm{K}^{-1} \mathrm{~kg}^{-1}\right)$. Four spatially explicit estimates of LCL are found by applying Eq. (4) to several combinations of near-surface forcing data, and two point-wise estimated are derived from the flux tower data. The atmospheric states $P_{\text {srf }}$ and $T_{\text {air }}$ are directly provided by both reanalysis products and the tower measurements. The measure of atmospheric moisture, $T_{\mathrm{dew}}$, is calculated for GLDAS, MERRA, and the tower sites separately using the respective near-surface humidity, temperature, and pressure data from each data set. The four distributed estimates of LCL are calculated with Eq. (4) by (1) using GLDAS for pressure and both temperatures, (2) using MERRA for pressure and both temperatures, (3) using pressure from MERRA and temperatures from GLDAS, and (4) using pressure from GLDAS and temperatures from MERRA. The LCL is quality controlled by limiting LCL to be less than the surface pressure.

\section{Results}

\subsection{Validation of simulated soil moisture and evapotranspiration}

The two model configurations are separately validated against the observationally estimated soil moisture and evapotranspiration on monthly and seasonal timescales, respectively. Figure $2 \mathrm{a}$ shows the time series of the area-averaged $\left(10-15^{\circ} \mathrm{S}, 120-150^{\circ} \mathrm{E}\right)$ normalized ensemble mean first layer soil moisture from the CTRL and the DRY ensembles and the AMSR-E observed data. The simulation dynamics are evaluated using the normalized $\mathrm{SM}_{1}$ due to the difficulties in direct comparison of simulated and observed soil moisture (Koster et al., 2009). The strong seasonal cycle of soil moisture owing to the monsoonal climate is evident in both the observationally based estimates and the simulations. CTRL and DRY are nearly identical, aside from the dry season in 2005 where the soil moisture in CTRL decreases more than that from DRY. The observed moistening of the soil following the dry seasons in Fig. 2a occurs within a month of that 

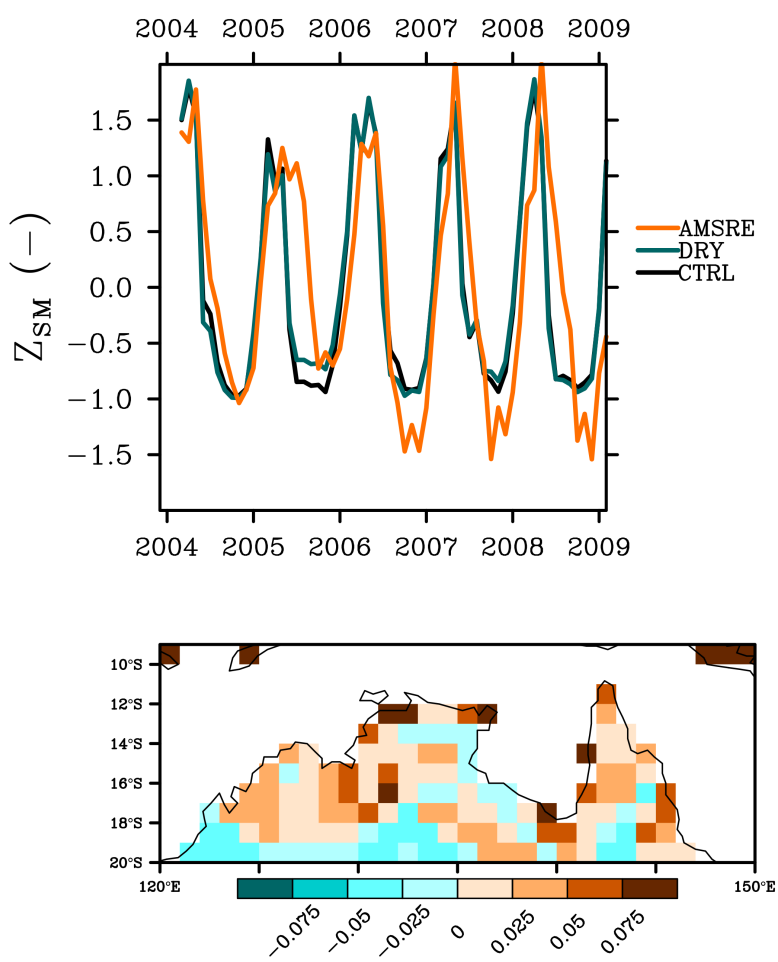

Figure 2. (a) The mean normalized (using the first two moments) first layer soil moisture $\left(\mathrm{SM}_{1}\right)$ from the CTRL and DRY simulations and the AMSR-E observations. (b) The difference between the mean $\mathrm{SM}_{1}$ (from all simulations over all months from 2004 to 2009) and the AMSR-E observations.

of the simulated moistening. The mean monthly soil moisture closely follows the observationally based estimates and exhibits dynamic behavior independent of the model configuration.

The bias of the ensemble-mean-time-averaged surface layer soil moisture from the eight simulations against the AMSR-E product is shown in Fig. 2b. Over large regions of northern Australia, the simulated $\mathrm{SM}_{1}$ is within $0.025 \mathrm{~mm}^{3} \mathrm{~mm}^{-3}$ of AMSR-E. The difference in mean $\mathrm{SM}_{1}$ between the two model configurations is similarly small (figure not shown). Figure 2 demonstrates that the temporal evolution (Fig. 2a) and mean state (Fig. 2b) of the simulated $\mathrm{SM}_{1}$ are similar to the AMSR-E estimates.

The seasonal mean ET is validated against the arithmetic mean of the three gridded ET products for both DJF (Fig. 3a, c, e) and SON (Fig. 3b, d, f). The observed DJF ET (Fig. 3e) has a strong north-south gradient with a maxima centered around $13^{\circ} \mathrm{S}, 130^{\circ} \mathrm{E}$. The strong north-south gradient is also present in the ensemble mean ET (Fig. 3a); however, the simulations overestimate DJF ET over much of the domain. The observationally based estimates show an ET of less than $50 \mathrm{~W} \mathrm{~m}^{-2}$ south of $18^{\circ} \mathrm{S}$ while the simulations remain above $60 \mathrm{~W} \mathrm{~m}^{-2}$ in this region. The mean SON ET is markedly lower compared to DJF ET in both the gridded data
(Fig. 3f) and the simulations (Fig. 3b). Similar to DJF, both the model and the ET product show a strong north-south gradient. The simulations underestimate the ET in the York Peninsula (east of $140^{\circ} \mathrm{E}$ and north of $17^{\circ} \mathrm{S}$ ) during SON and overestimate the ET in this region during DJF. The overestimation of DJF ET compared to the gridded product is much more pronounced for the CTRL simulations (Fig. 3a) than for the DRY simulations (Fig. 3c). The underestimation of the SON ET in the simulations is largely a result of including the DRY model configuration. The CTRL simulations exhibit a $10-20 \mathrm{~W} \mathrm{~m}^{-2}$ increase in SON ET over the DRY model runs (Fig. 3b, d). Overall, the model exhibits spatiotemporal ET in close agreement with this gridded ET product.

Point measurements of SM and ET at two locations show reasonable agreement with the model simulations. The Howard Springs SM observations $10 \mathrm{~cm}$ depth (Fig. 4a) typically increases from 0.05 to $0.2 \mathrm{~mm}^{3} \mathrm{~mm}^{-3}$ from the dry to the wet season. The observations are drier during the wet season and have a smaller (by a factor of 2) seasonal cycle than both the DRY and CTRL simulations. DRY is much drier $\left(\sim 0.08 \mathrm{~mm}^{3} \mathrm{~mm}^{-3}\right)$ than CTRL $\left(\sim 0.18 \mathrm{~mm}^{3} \mathrm{~mm}^{-3}\right)$ during the dry season and in better agreement with the measurements $\left(\sim 0.05 \mathrm{~mm}^{3} \mathrm{~mm}^{-3}\right)$. This contrasts with the agreement at the Adelaide River site (Fig. 4b) where the measurements and CTRL peak at around $0.30 \mathrm{~mm}^{3} \mathrm{~mm}^{-3}$ during the 2008 wet season. DRY $\left(0.02-0.07 \mathrm{~mm}^{3} \mathrm{~mm}^{-3}\right)$ is again much drier than CTRL $\left(0.15 \mathrm{~mm}^{3} \mathrm{~mm}^{-3}\right)$ during the 2008 dry season but CTRL is in better agreement with the data $\left(0.15 \mathrm{~mm}^{3} \mathrm{~mm}^{-3}\right)$. The AMSR-E estimate, CTRL, and DRY are similar in Fig. $4 \mathrm{a}$ and $\mathrm{b}$ (the $y$ axis scale is the same in both figures), while the SM observations at the two sites differ drastically. The disagreement in the mean as well as the amplitude of the seasonal variability is likely due to both the difference in scale between the measurements and simulations and poor representation of soil properties in the model. When the SM comparison is normalized using the first two moments as in Fig. 2a (not shown) there is greater agreement between the measurements, AMSR-E, and the simulations.

The ET data at Howard Springs (Fig. 4c) demonstrates that the CTRL simulation always produces too little ET during the dry season. While the gridded ET estimate in Fig. 4c falls within $10 \mathrm{Wm}^{-2}$ of the CTRL simulation during the dry season, the tower data are nearly $20 \mathrm{~W} \mathrm{~m}^{-2}$ greater than during both the 2007 and 2008 dry seasons. The wet season peak in ET is well simulated by both CTRL and DRY at Howard Springs. The model performance is different at the Adelaide River as both CTRL and DRY have a wet season peak ET of around $120 \mathrm{~W} \mathrm{~m}^{-2}$ while the measurements peak closer to $150 \mathrm{~W} \mathrm{~m}^{-2}$. Figure $4 \mathrm{~d}$ further demonstrates that DRY has too little dry season ET.

The results from Figs. 2, 3, and 4 demonstrate that CLM4 simulates the monthly and seasonal first layer soil moisture and evapotranspiration reasonably. While the details of the model performance vary depending on which site, season, and ensemble member are used for validation; overall, the 

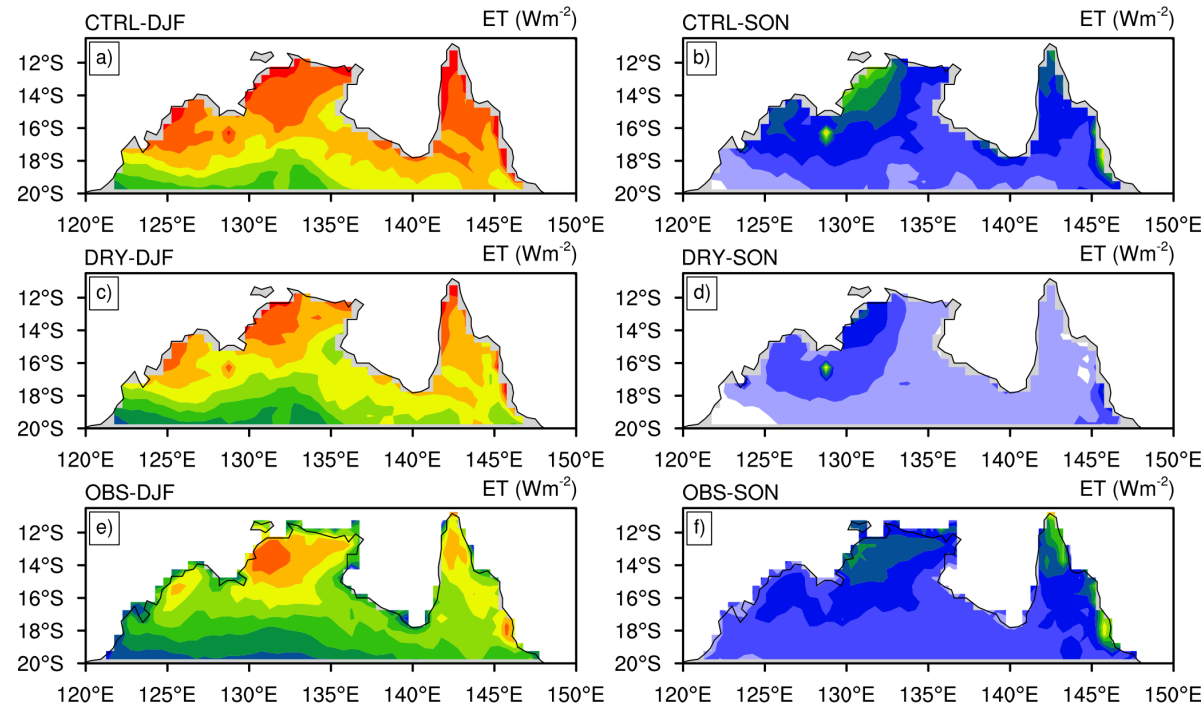

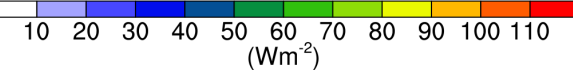

Figure 3. The mean ET $\left(\mathrm{Wm}^{-2}\right)$ from the wet season (DJF shown in the left hand column) and the transition between the dry and wet seasons (SON shown in the right hand column). The ensemble mean ET from (a) CTRL over DJF, (b) CTRL over SON, (c) DRY for DJF, (d) DRY from SON, (e) OBS (the mean of three gridded ET products) over DJF, and (f) OBS for SON.

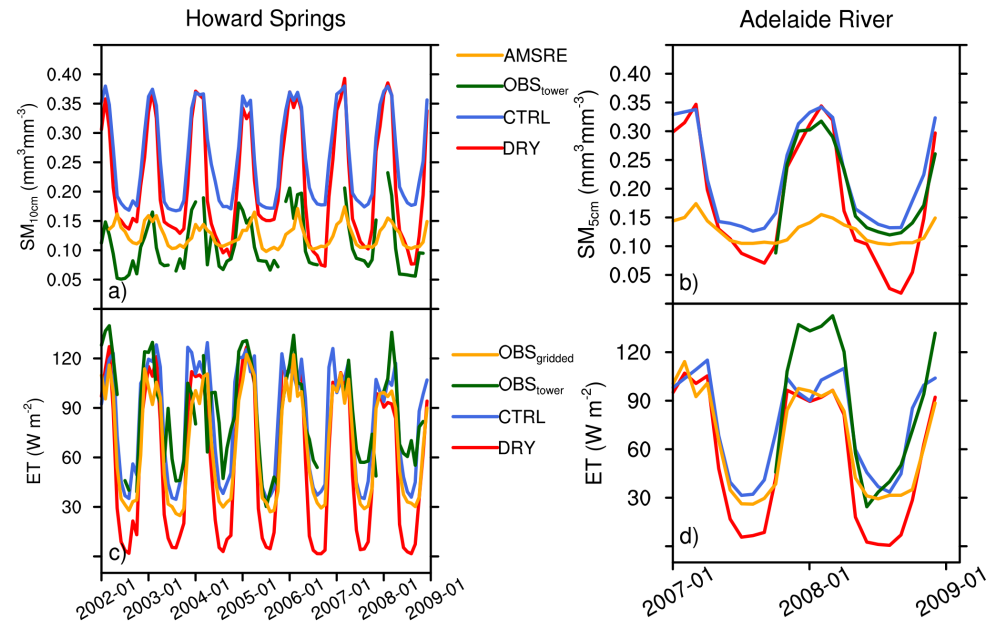

Figure 4. The monthly soil moisture (SM in $\mathrm{mm}^{3} \mathrm{~mm}^{-3}$ ) from the ensemble mean from CTRL and DRY, AMSR-E, and flux tower measurements $\left(\mathrm{OBS}_{\text {tower }}\right)$ from flux tower sites at (a) Howard Springs at $10 \mathrm{~cm}$ depth and (b) Adelaide River at $5 \mathrm{~cm}$ depth. The monthly evapotranspiration $\left(\mathrm{ET}\right.$ in $\left.\mathrm{Wm}^{-2}\right)$ from CTRL, DRY, the mean of three ET products $\left(\mathrm{OBS}_{\text {gridded }}\right)$ and the measurements at the (c) Howard Springs and (d) Adelaide River flux tower sites.

spatial and temporal patterns of ET and SM are generally captured by the modeling system. The accuracy of the estimated land surface states and fluxes therefore enables the use of the simulated variables in the diagnoses of the landatmosphere association strength during SON and DJF.

\subsection{Background SM state}

The sharp contrast in background SM state can be illustrated by taking a spatiotemporal average of SM as a function of depth for CTRL and DRY for DJF (Fig. 5a) and SON (Fig. 5b). The soil moisture away from the surface is markedly different between CTRL and DRY. During DJF, CTRL shows a slight increase in soil moisture with depth, reaching a peak of $\sim 0.35 \mathrm{~mm}^{3} \mathrm{~mm}^{-3}$ at depths near 


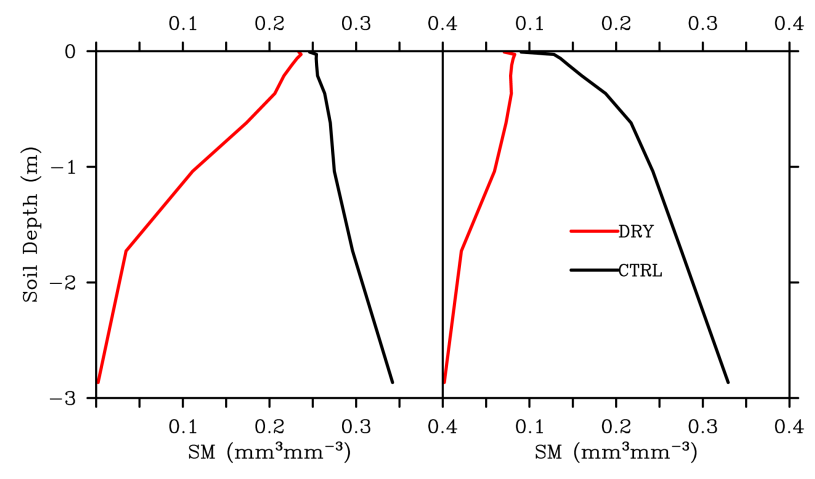

Figure 5. Spatiotemporal mean soil moisture $\left(\mathrm{mm}^{3} \mathrm{~mm}^{-3}\right) \mathrm{SM}$ as a function of depth (m) for (a) DJF and (b) SON.

$3 \mathrm{~m}$. In contrast, DRY has a peak soil moisture of only $\sim 0.24 \mathrm{~mm}^{3} \mathrm{~mm}^{-3}$ at the surface and decreases with depth to near zero at $3 \mathrm{~m}$. Similar patterns of SM with depth are seen over SON; however, $\mathrm{SM}_{1}$ is considerably lower for both CTRL and DRY compared to DJF.

Despite the similar mean and temporal behavior of $\mathrm{SM}_{1}$ shown in Fig. 2, SM away from the surface differs substantially between the two model configurations (Fig. 5). The mean DJF ET is similar between CTRL and DRY, with differences between the two of only $10-20 \mathrm{~W} \mathrm{~m}^{-2}$, corresponding to roughly $10-20 \%$ of the mean value. The fractional contribution of transpiration to the total ET during DJF is roughly $10-30 \%$ for both DRY and CTRL (Fig. 6), indicating that the evaporation is the dominant ET mechanism. The enhanced mean SM in CTRL causes the CTRL ET to be greater than the DRY ET during DJF, yet both compare reasonably well to the observationally based estimates (Fig. 3). However, the lack of SM at depths below several centimeters for DRY during SON causes the reduced ET as compared to CTRL during this period. The mean ET during SON is sensitive to the mean SM away from the surface, indicating that transpiration significantly contributes to the total ET during this period as can be seen in Fig. 6. The large contribution of transpiration to the total ET in CTRL (Fig. 6b) is facilitated by the moist subsurface soil moisture (Fig. 5b). The reduced root zone SM in DRY leads to an increase in water stress and reduced transpiration, causing both the lower mean ET and transpiration fraction in DRY relative to CTRL. This reduction during SON is large relative to the mean ET during the period (Fig. 3).

\subsection{Correspondence: EF-LCL and $\mathrm{SM}_{1}-\mathrm{LCL}$}

The statistical association between the evaporative fraction and the LCL is shown in Fig. 7, with the results from the two flux towers shown in enclosed squares around $13^{\circ} \mathrm{N}, 131^{\circ} \mathrm{E}$. The insignificant associations are greyed out while the statistically significant results are shown in color. During DJF, CTRL (Fig. 7a) and DRY (Fig. 7c) exhibit strong surface flux-atmosphere correspondence, with the strongest association over the Cape York Peninsula (east of $140^{\circ} \mathrm{E}$ and north of $17^{\circ} \mathrm{S}$ ) and the southwestern part of the domain. Similarly, the EF-LCL association is significant during SON (Figs. 7b, d) over much of the domain, although the magnitude is reduced relative to DJF. Both ensembles show strong associations independent of the season; however, the differences between CTRL and DRY vary with season. The DJF EF-LCL correspondence near $15^{\circ} \mathrm{S}, 132^{\circ} \mathrm{E}$ is statistically significant in DRY (Fig. 7c) but not in CTRL (Fig. 7a), contrasting the similar SON EF-LCL association in this region exhibited by both DRY (Fig. 7d) and CTRL (Fig. 7b). The flux towers (boxed squares in Fig.7a-c) show statistically significant association between EF and the LCL during both seasons. The EF-LCL correspondence from the tower observations agree more closely with DRY in DJF as CTRL shows statistically insignificant association in the region $\left(13^{\circ} \mathrm{S}, 131^{\circ} \mathrm{E}\right)$. The reduced deep layer soil moisture resulting from the removal of the groundwater module enhances the DJF correspondence in agreement with the tower data.

Figure 8 shows the median $K \tau$ between $\mathrm{SM}_{1}$ and the LCL (see Sect. 3.3) for CTRL and DRY separately during DJF (Fig. 8a, c) and SON (Fig. 8b, d). Several important features are present in Fig. 8. The $\mathrm{SM}_{1}-\mathrm{LCL}$ association during DJF and SON is largely similar between the two model configurations. CTRL (Fig. 8a) and DRY (Fig. 8c) exhibit similar spatial patterns and magnitudes of $K \tau$. Some regions $\left(17^{\circ} \mathrm{S}\right.$, $126^{\circ} \mathrm{E}$ ) exhibit increases in the magnitude of $K \tau$ in CTRL relative to DRY in DJF (Fig. 8a, c) although the differences are statistically insignificant over most of the domain. Regardless of these slight variations in $K \tau$, CTRL and DRY exhibit a strong association between $\mathrm{SM}_{1}$ and the boundary layer during the peak of the wet season over coincident parts of the domain. Both model configurations also show areas $\left(15^{\circ} \mathrm{S}, 131^{\circ} \mathrm{E}\right)$ with insignificant correspondence adjacent to the strongly associated regions. In contrast, CTRL and DRY both contain regions of significant positive $K \tau$ demonstrating a negative correspondence during SON, in disagreement with the results from the Adelaide River tower site. The tower sites show statistically significant negative SM-LCL association during DJF adjacent to a region $\left(15^{\circ} \mathrm{S}, 131^{\circ} \mathrm{E}\right)$ of insignificant correspondence in both simulations. The similarity in $\mathrm{SM}_{1}-\mathrm{LCL}$ correspondence between CTRL and DRY during both DJF and SON implies a similar temporal variability of $\mathrm{SM}_{1}$ as related to the LCL. From Fig. 3, the mean ET fluxes are considerably different during SON. The similar temporal behavior relative to the LCL for both DRY and CTRL indicates that the $\mathrm{SM}_{1}$ variability is physically independent of the season's mean ET fluxes.

Contrasting Figs. 7 and 8 reveals that the surface fluxes (Fig. 7b, d) are associated with the LCL despite the simulated surface layer soil moisture (Fig. 8b, d) lacking similar correspondence. The regions of positive $K \tau$ in Fig. 8 contradict the strongly negative $K \tau$ in Fig. 7 during SON. The flux towers show negative association for both EF-LCL and SM- 

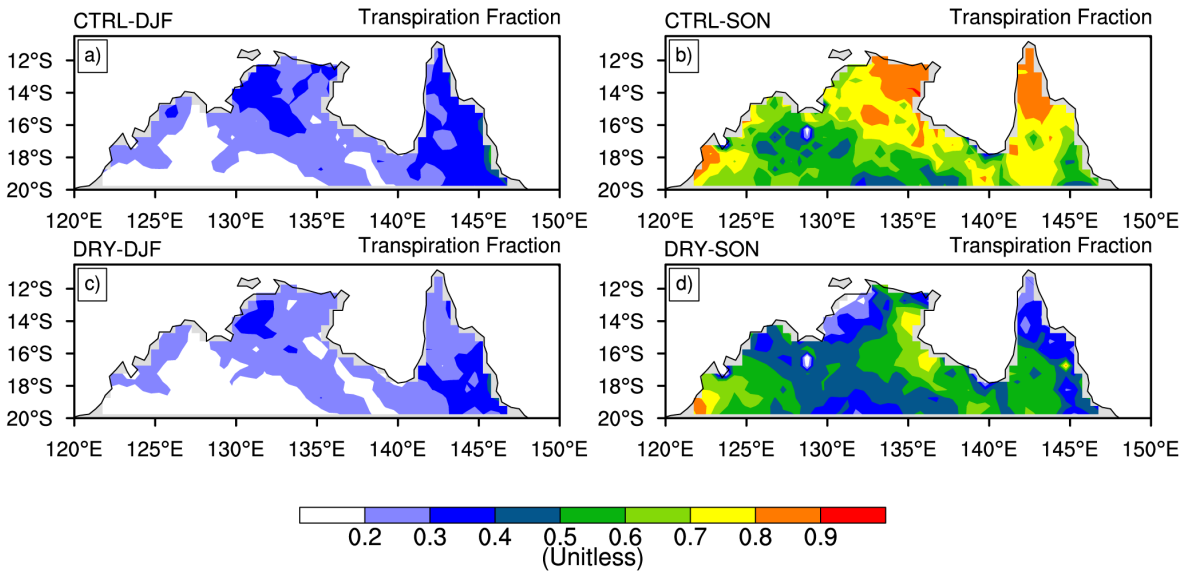

Figure 6. The mean transpiration fraction (fraction of total ET from transpiration defined as the ratio of transpiration over total ET) from the wet season (DJF shown in the left hand column) and the transition between the dry and wet seasons (SON shown in the right hand column). The ensemble mean transpiration fraction to total ET from (a) CTRL over DJF, (b) CTRL over SON, (c) DRY over DJF, and (d) DRY over SON.

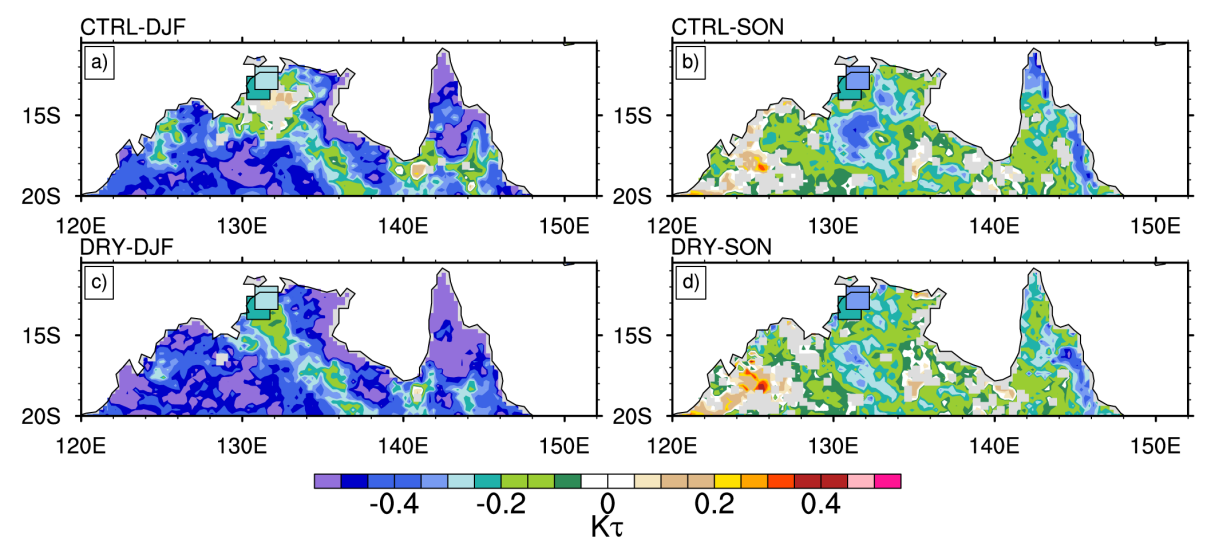

Figure 7. The ensemble median $K \tau$ correlation metric between the afternoon time (local) EF and the afternoon computed LCL from (a) CTRL over DJF, (b) CTRL over SON, (c) DRY over DJF, and (d) DRY over SON. The black outlined squares in (a-d) denote the values from the flux tower sites. Only statistically significant (95\% confidence level) results are shown in (a-d).

LCL during DJF and SON in Figs. 7 and 8. The EF-LCL correspondence during DJF is much stronger than the correlation from $\mathrm{SM}_{1}$, and DRY exhibits regions of stronger $\mathrm{EF}-$ LCL correspondence than CTRL; however, the differences are not statistically significant over much of the domain. A key difference between the flux tower and model simulation estimated $K \tau$ is the depth of the SM. The measurement depth at the tower sites are 5 and $10 \mathrm{~cm}$ for Adelaide River and Howard Springs respectively, while the model surface layer soil moisture is taken from a depth of $0.7 \mathrm{~cm}$. The change in sign of $\mathrm{SM}_{1}-\mathrm{LCL} K \tau$ from SON (Fig. 8b, d) to DJF (Fig. 8a, c) demonstrates that applying Eq. (4) to $\mathrm{SM}_{1}$ and the LCL does not always capture the co-evolution of the land surface and the atmosphere during periods where deep SM and transpiration dominate the ET flux.

In short, our results demonstrate that the simulated surface layer soil moisture cannot adequately capture the SM-LCL association during both DJF and SON. The significant contributions of transpiration to the total ET fluxes (especially during $\mathrm{SON}$ ) are responsive to perturbations in $\mathrm{SM}_{\mathrm{rz}}$ and not $\mathrm{SM}_{1}$.

\subsection{Proposed Association strength definition: $\mathbf{S M}_{\mathrm{rz}}-\mathbf{L C L}$}

The definition of a statistical metric that captures the relationship between land surface moisture states and fluxes must encompass the relevant physical mechanisms. Previously, observationally derived values of $K \tau$ were limited to using $\mathrm{SM}_{1}$ because the AMSR-E (or other microwave) SM measurements typically measure to depths of less than a few centimeters beneath the soil surface (Ferguson et al., 2012). Computing $K \tau$ between $\mathrm{SM}_{1}$ and the LCL incorporates the surface layer soil moisture that is important for surface evap- 


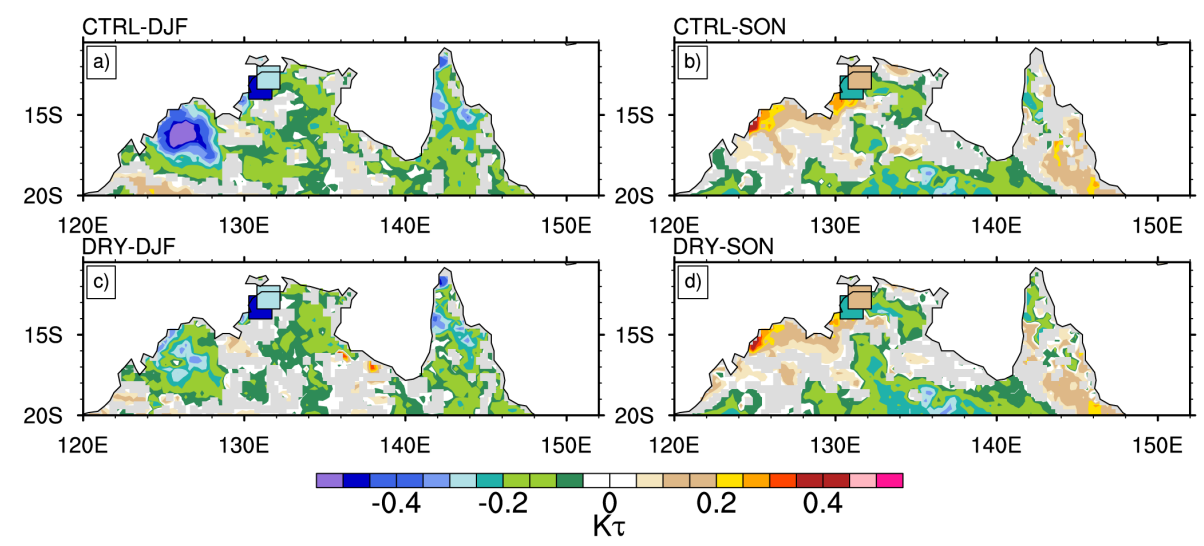

Figure 8. The ensemble median $K \tau$ correlation metric between the morning first layer soil moisture ( $\left.\mathrm{SM}_{1}\right)$ and the afternoon computed LCL from (a) CTRL over DJF, (b) CTRL over SON, (c) DRY over DJF, and (d) DRY over SON. The black outlined squares in (a-d) denote the values from the flux tower sites. Only statistically significant (95\% confidence level) results are shown in (a-d).

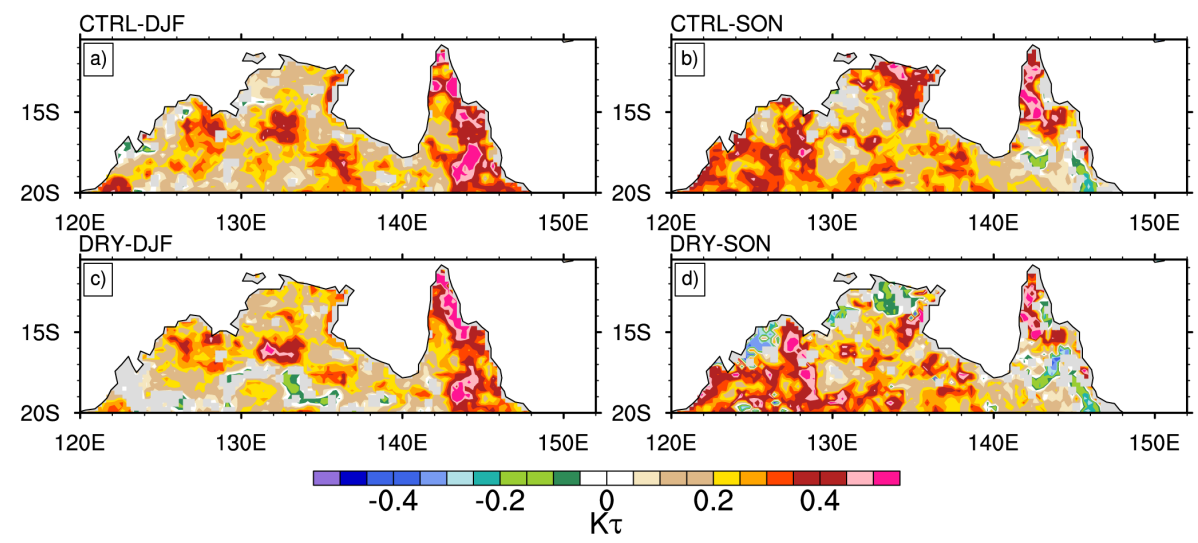

Figure 9. The ensemble median $K \tau$ correlation metric between the morning root zone soil moisture $\left(\mathrm{SM}_{\mathrm{rz}}\right)$ and the afternoon computed LCL from (a) CTRL over DJF, (b) CTRL over SON, (c) DRY over DJF, and (d) DRY over SON. The black outlined squares in (a-d) denote the values from the Howard Springs flux tower site. Only statistically significant (95\% confidence level) results are shown in (a-d).

oration from the soil. Therefore, the relationship between the temporal variations in SM and the LCL in DJF (or other periods where the ET is largely comprised of soil evaporation) can be adequately defined using $\mathrm{SM}_{1} . K \tau$ computed from $\mathrm{SM}_{1}$ neglects $\mathrm{SM}_{\mathrm{rz}}$ variations that drive transpiration during the initial increase in precipitation following the dry season and therefore may not fully encompass the extent of landatmosphere associations. Acknowledging the importance of transpiration during the northern Australian wet season, we further evaluate the land-atmosphere association by computing $K \tau$ between the vertically averaged $\mathrm{SM}_{\mathrm{rz}}$ and the LCL. As opposed to remotely sensed SM from AMSR-E (or other satellite products), the use of simulated SM facilitates the estimation of $\mathrm{SM}_{\mathrm{rz}}$. Applying Eq. (4) using $\mathrm{SM}_{\mathrm{rz}}$ imposes a different set of problems, as the rooting depth is model dependent and generally only approximately known. There is substantial evidence that eucalypts have rooting depths exceeding $20 \mathrm{~m}$ (Schenk and Jackson 2002), however neither CLM4 nor the direct observations in this study extend that deep. Due to these limitations, $\mathrm{SM}_{\mathrm{rz}}$ is computed as the weighted mean of the SM observations at 10, 40, and $100 \mathrm{~cm}$ for the Howard Springs site. We assume that the $\mathrm{SM}_{\mathrm{rz}}$ consists of the soil layers between the surface and a depth of $1 \mathrm{~m}$, as more than $90 \%$ of the prescribed roots in CLM 4 are within $1 \mathrm{~m}$ of the surface (Oleson et al., 2010). This assumed rooting depth is consistent with the model formulation but not realistic given the rooting depths of eucalypts.

Figure 9 shows the ensemble median $K \tau$ diagnosed between $\mathrm{SM}_{\mathrm{rz}}$ and the LCL. Comparing Figures 8 and 9 it is clear that including the portion of SM that partially controls transpiration increases the magnitude of the DJF SM-LCL associations and eliminates the region near $14^{\circ} \mathrm{S}, 131^{\circ} \mathrm{E}$ with statistically insignificant correspondence (Fig. 8a, c) despite soil evaporation contributing significantly to the simulated ET. Large differences between the SON SM $\mathrm{rz}_{\mathrm{rz}}-\mathrm{LCL}$ and $\mathrm{SM}_{1}-\mathrm{LCL} K \tau$ are seen south of $15^{\circ} \mathrm{S}$ and east of $130^{\circ} \mathrm{E}$. Despite large regions of statistically significant $\mathrm{SON} \mathrm{SM} \mathrm{rz}^{-}$ LCL, $K \tau$ for CTRL (Fig. 9b) and DRY (Fig. 9d) regions 


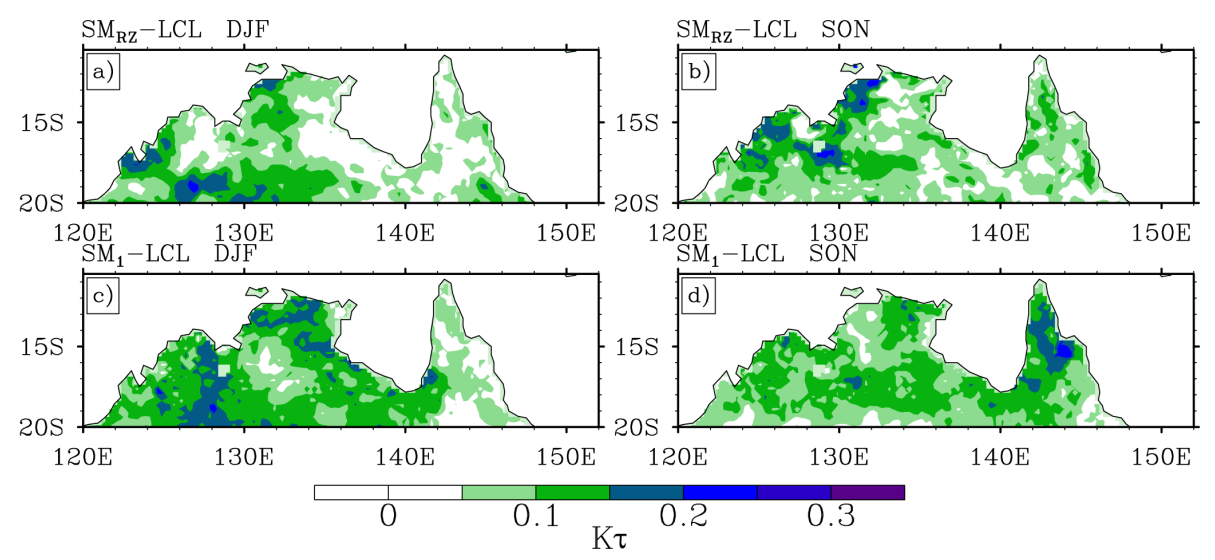

Figure 10. The standard deviation of the $K \tau$ correlation metric among the ensemble members between the afternoon computed LCL and either the morning root zone soil moisture $\left(\mathrm{SM}_{\mathrm{rz}}\right)$ over (a) DJF and (b) SON or the morning first layer soil moisture $\left(\mathrm{SM}_{1}\right)$ over $(\mathbf{c}) \mathrm{DJF}_{\mathrm{f}}$ and (d) SON.

of insignificant association are prevalent near $13^{\circ} \mathrm{S}, 131^{\circ} \mathrm{E}$. The flux-tower-derived SON SM $\mathrm{rz}_{\mathrm{z}}-\mathrm{LCL}$ correspondence is insignificant in agreement with the DRY and CTRL results near $13^{\circ} \mathrm{S}, 131^{\circ} \mathrm{E}$. The similarity between the DRY and CTRL $\mathrm{SM}_{\mathrm{rz}}-\mathrm{LCL} K \tau$ highlights the negligible groundwater impact (Fig. 9b, d). Comparing Fig. 9b and d with Fig. 3b and $\mathrm{d}$ reveals that despite the impact of groundwater on the mean ET flux over SON, the mean state of the deep SM imparts little influence on the temporal dynamics of $\mathrm{SM}_{\mathrm{rz}}$ in relation to the LCL. Neglecting the SM beneath the surface layer in the calculation of $K \tau$ results in a weak diagnosis of SM-LCL association during SON because transpiration is partly governed by the water availability within the root zone. By defining the association using $\mathrm{SM}_{\mathrm{rz}}$, it is clear that the land is strongly linked to the LCL during both DJF and SON. The DJF SM-LCL association in CTRL near flux tower sites is stronger when defined in this manner, although both sets of simulations still show $\mathrm{SM}_{\mathrm{rz}}$ to be statistically associated to the LCL.

The $\mathrm{SM}_{1}-\mathrm{LCL}$ and $\mathrm{SM}_{\mathrm{rz}}-\mathrm{LCL} K \tau$ shown in Figs. 8 and 9 are the median from ensembles with 32 estimates. The ensembles explicitly use multiple constructions of LCL to sample the possible range of atmospheric states given the nearsurface MERRA and GLDAS estimates and may lead to uncertain estimates of $K \tau$. The inter-ensemble uncertainty of the $K \tau$ metric is examined to demonstrate the robustness of the results. The standard deviation of the association between $\mathrm{SM}_{\mathrm{rz}}$ and the LCL and between $\mathrm{SM}_{1}$ and the LCL among the ensemble members is generally less than 0.15 (Fig. 10a-d). The variation among the ensemble members is smaller than the median $K \tau$ shown in Figs. 8 and 9. The low standard deviation relative to the median demonstrates that the association shown in Figs. 8 and 9 is robust, since more than $83 \%$ of the $K \tau$ estimates (assuming they are normally distributed) have a correspondence of the same sign reported in the figures. The correspondence using $\mathrm{SM}_{1}$ (Fig. 10c) shows larger ensemble uncertainty near the coast centered around $135^{\circ} \mathrm{E}$ compared to the $\mathrm{SM}_{\mathrm{rz}}$ association in DJF (Fig. 10a) and over the Cape York Peninsula in SON (Fig. 10b, a). Aside from the region near $15^{\circ} \mathrm{S}, 130^{\circ} \mathrm{E}$ during $\mathrm{SON}$, the larger ensemble uncertainty is found when using $\mathrm{SM}_{1}$ to define the correspondence.

\section{Discussion}

The seasonal ET from CTRL, DRY, and the gridded ET products from DJF through SON provide insight into the mechanisms that limit the SON DRY ET. The ET from CTRL and DRY are similar (within $\pm 10 \%$ ) during the large DJF precipitation forcing. The dry season commences between MAM (March-April-May) and JJA (June-July-August; Fig. 1) resulting in increased vapor pressure deficit (VPD) between the vegetation and the atmosphere and increased photosynthetically active radiation (PAR). The changes in VPD and PAR promote increased transpiration from DJF through MAM, although the actual transpiration is also governed by $\mathrm{SM}_{\mathrm{rz}}$. Comparing Figs. 3, 5, and 6 indicates that the DRY ET is relatively SM limited and unable to maintain ET similar in magnitude to CTRL and the observationally based estimates during SON. The SM limitation causes a reduction in the total ET by limiting the amount of transpiration (Fig. 6d). Within the model, the soil column-groundwater interactions parameterized in CTRL inhibit the large, ET limiting $\mathrm{SM}_{\mathrm{rz}}$ reduction present in DRY. In reality, the inability of DRY to maintain ET during SON may result from the shallow rooting depths assumed in CLM4. The depths are substantially shallower than the rooting depths of eucalypts. Realistic rooting depth profiles reaching nearly $20 \mathrm{~m}$ in Australia (Schenk and Jackson, 2002) and corresponding soil layer depths may negate the impact of the parameterized soil column-groundwater impacts current in CLM4. 
The EF-LCL association (Fig. 7) is similar for both model configurations despite the mean ET (Fig. 3), SM (Fig. 5) and transpiration fraction (Fig. 6) differing considerably between CTRL and DRY. The EF-LCL similarity holds for both DJF and SON despite the differing background soil moisture states between the two periods and differing contributions of transpiration to the total ET (Fig. 6). The results indicate that while the mean ET and transpiration fraction is a strong function of mean soil moisture, the SM-LCL association diagnosed using offline simulations of SM and EF with an observationally estimated LCL is insensitive to the background state. The coincidence of the temporal variations in SM, EF, and LCL are demonstrated by the large values of $K \tau$. These seemingly counterintuitive results may be an artifact of using a rank correlation coefficient to determine the strength of the correspondence. $K \tau$ only measures the temporal coincidence of the two time series while neglecting the magnitude of these variations. Therefore, $K \tau$ cannot distinguish between a dry SM state with the small evaporative fluxes and a wet state with large fluxes if the timing of the SM and flux variations are identical. Although $K \tau$ is largely independent to the background soil moisture state, alternative definitions of association may not remain as invariant.

While association in Fig. 7 is largely unaffected by the mean SM state, the mean ET flux is largely derived from deeper SM through transpiration during the onset of the wet season prior to DJF. The statistical relationship between soil moisture and the boundary layer under these conditions is poorly defined using $\mathrm{SM}_{1}$. The consistent EF-LCL coevolution during SON and DJF highlights the inadequacy of characterizing land-atmosphere processes using only $\mathrm{SM}_{1}$. Attempting to define the SM-LCL relationship with $\mathrm{SM}_{1}$ results in a physically improbable conclusion where $K \tau$ transitions from positive (Fig. 7b) to negative (Fig. 7a) as the wet season is established (Fig. 1) and directly contradicts the EF-LCL results. Despite the domain's mean precipitation increasing from roughly zero to several millimeters per day during SON, $K \tau$ from $\mathrm{SM}_{1}-\mathrm{LCL}$ is both positive (i.e., $15^{\circ} \mathrm{S}, 126^{\circ} \mathrm{E}$ ) and negative (i.e., $15^{\circ} \mathrm{S}, 134^{\circ} \mathrm{E}$ ) over this period. The transition from negligible (or positive) to strong statistical rank correlation between the soil moisture and the atmosphere during the wet season is an artifact resulting from the use of $\mathrm{SM}_{1}$. More consistent correspondence in general agreement with the EF-LCL dynamics throughout the wet season exists between $\mathrm{SM}_{\mathrm{rz}}$ and LCL because transpiration is incorporated into the diagnostic. During SON, the dry surface layer SM is responsible for little ET, so variations in ET are not associated with variations in $\mathrm{SM}_{1}$. The $\mathrm{SM}_{\mathrm{rz}}-\mathrm{LCL}$ $K \tau$ eliminates the insignificant association around $17^{\circ} \mathrm{S}$, $128^{\circ} \mathrm{E}$ exhibited in the $\mathrm{SM}_{1}-\mathrm{LCL}$ metric. Despite regions of significant $\mathrm{SM}_{\mathrm{rz}}-\mathrm{LCL}$ association in DRY and CTRL, the Howard Springs data show insignificant $\mathrm{SM}_{\mathrm{rz}}-\mathrm{LCL}$ correspondence during SON. The lack of observed association is possibly related to the inability to sample SM at depths that correspond to the physically relevant rooting depths. The ne- cessity of using $\mathrm{SM}_{\mathrm{RZ}}$ agrees with Lee et al. (2012), where transpiration was found to limit precipitation variability over tropical regions. The importance of transpiration among the various ET components is not limited to northern Australia or monsoon regions (Coenders-Gerrits et al., 2014; Schlesinger and Jasechko, 2014), highlighting the need to characterize land-atmosphere dynamics using SM well beneath the surface.

Statistically determing the association using only nearsurface variables from land surface model simulations and atmospheric data as done in this study (i.e. Ferguson et al., 2012; Betts, 2009) is limited due to only examining a part of the full land-atmosphere coupling processes. While the LCL is an important determinant in the formation of precipitation, moisture convergence, upper level inversions, convective available potential energy, wind shear, and many other factors play important roles in the formation of convection. The correspondence diagnosed in this study with Eq. (4) is by definition limited in scope to only part of the coupling continuum described in Eq. (1). Therefore, an association defined using these methods provides a necessary but not sufficient condition for strong land-atmosphere interactions between soil moisture and precipitation.

Our results likely extend to monsoonal regions beyond northern Australia. GLACE (Global Land-Atmosphere Coupling Experiment; Koster et al., 2006) revealed multiple areas of strong land-atmosphere coupling coincide with major monsoon systems. The strong co-evolution during the wet season (September-February) diagnosed using $\mathrm{SM}_{\mathrm{rz}}$ and $K \tau$ in our results qualitatively agrees with the strong coupling in monsoon regions from GLACE. The dry season antecedent to the large precipitation fluxes induces low evaporation while allowing deeply rooted plants to transpire despite the prolonged dry period. These conditions over northern Australia (Figs. 3, 4) lead to transpiration dominating the ET flux during the onset of the wet season. The behavior of the land-atmosphere system as diagnosed using $K \tau$ under these conditions must be defined using $\mathrm{SM}_{\mathrm{rz}}$ rather than $\mathrm{SM}_{1}$ to ensure the relevant pathways of the moisture fluxes are not neglected.

Our results demonstrate the necessity of capturing the relevant physical processes when designing a metric to evaluate the relationship between the land and the atmosphere. The contradiction between the SON SM $1-\mathrm{LCL}$ and the EF-LCL relationships in our study suggests that the methods of Ferguson et al. (2012) will fail to find coupling during periods when the land surface fluxes respond to $\mathrm{SM}_{\mathrm{rz}}$ but not $\mathrm{SM}_{1}$. Future research that investigates SM-LCL using $K \tau$ within a fully coupled land-atmosphere system should not neglect $\mathrm{SM}_{\mathrm{rz}}$ in favor of $\mathrm{SM}_{1}$. Failure to incorporate the relevant $\mathrm{SM}$ information would directly limit the situations for which the diagnosed coupling is valid. 


\section{Conclusions}

The feasibility of diagnosing the land-atmosphere relationship using a rank correlation coefficient is analyzed utilizing ensembles of land surface simulations and near-surface atmospheric data. Using four forcing data sets, ensembles of CLM simulations over northern Australia are performed, using configurations that intentionally span a range of mean SM states by either including or neglecting soil columngroundwater interactions. The seasonal dynamics of the simulated $\mathrm{SM}_{1}$ is insensitive to the mean soil moisture state and all simulations compare favorably with the AMSR-E soil moisture product. Furthermore, the simulated ET from December to February is similar between the CTRL and DRY runs, with both configurations largely consistent with the DJF ET estimated from three gridded ET products.

The strength of the temporal co-evolution of land and atmosphere states is diagnosed between both $\mathrm{SM}_{1}$ and $\mathrm{EF}$ from the simulations and the LCL as calculated from the nearsurface atmospheric data. In line with the coupling strength found in previous studies, during the peak wet season strong $\mathrm{SM}_{1}-\mathrm{LCL}$ and EF-LCL associations are shown. The wet season onset (SON) shows large rank correlation coefficients between EF and LCL that contrasts the lack of correlation between $\mathrm{SM}_{1}$ and LCL. The contradicting correlations between EF-LCL and $\mathrm{SM}_{1}-\mathrm{LCL}$ demonstrate that the SON land-atmosphere relationship is not properly characterized with $\mathrm{SM}_{1}$. The land-atmosphere interactions during periods with non-negligible transpiration necessitates the use of root zone soil moisture instead of the surface soil moisture to properly capture the physical processes. The correlation between $\mathrm{SM}_{\mathrm{rz}}$ and LCL differs considerably from that between $\mathrm{SM}_{1}$ and LCL. The co-evolution of $\mathrm{SM}_{\mathrm{rz}}$ and LCL is shown by strong statistical correspondence throughout the wet season and is consistent with the co-evolution between EF and LCL. During the peak of the wet season, $\mathrm{SM}_{1}$ is sufficient to explain the SM-LCL association while during the monsoon season onset $\mathrm{SM}_{\mathrm{rz}}$ is necessary. The results demonstrate that the root zone soil moisture must be considered when diagnosing the relationship between SM and the LCL.

Our results show that the statistically diagnosed landatmosphere correspondence in offline simulations is insensitive to the mean vertical profile of soil moisture. It is, however, sensitive to the depth of the soil moisture considered. While the strong soil moisture-atmosphere associations shown here are a necessary but not sufficient condition to diagnose full land-atmosphere coupling, the results demonstrate the need to describe SM-LCL coupling using the physically relevant soil moisture. Studies that explore the behavior of the land-atmosphere system should use a statistical measure which encapsulates the SM that is physically relevant to the dominant processes. Future studies that evaluate land-atmosphere coupling using a full landatmosphere model environment risk not capturing regions of land-atmosphere coupling if only $\mathrm{SM}_{1}$ is considered. In or- der to evaluate coupling during periods when ET is dominated by transpiration, $\mathrm{SM}_{\mathrm{rz}}$ should be considered. We recommend that future studies of land-atmosphere coupling focus on root zone soil moisture rather than surface layer soil moisture.

Acknowledgements. We acknowledge support from the Australian Research Council Super Science scheme (FS100100054). A. J. Pitman was also supported by the Australian Research Council Centre of Excellence for Climate System Science (CE110001028). J. P. Evans was supported by an Australian Research Council Future Fellowship (FT110100576). The GLDAS data used in this study were acquired as part of the NASA's Earth-Sun System Division and archived and distributed by the Goddard Earth Sciences (GES) Data and Information Services Center (DISC) Distributed Active Archive Center (DAAC). We also thank Diego Miralles for providing the GLEAM ET product.

Edited by: P. Gentine

\section{References}

Betts, A. K.: Land-surface-atmosphere coupling in observations and models, J. Adv. Model. Earth Syst., 1, 4, doi:10.3894/JAMES.2009.1.4, 2009.

Betts, A. K., Ball, J. H., Beljaars, A. C. M., Miller, M. J., and Viterbo, P. A.: The land surface-atmosphere interaction: a review based on observational and global modeling perspectives, J. Geophys. Res., 101, 7209-7225, doi:10.1029/95JD02135, 1996.

Betts, A. K., Helliker, B., and Berry, J.: Coupling between $\mathrm{CO}_{2}$, water vapor, temperature, and radon and their fluxes in an idealized equilibrium boundary layer over land, J. Geophys. Res., 109, 7209-7225, doi:10.1029/2003JD004420, 2004.

Beringer, J.: Adelaide River OzFlux tower site, OzFlux: Australian and New Zealand Flux Research and Monitoring, hdl:102.100.100/14228, CSIRO, Dickson, Australia, 2013a.

Beringer, J.: Howard Springs OzFlux tower site, OzFlux: Australian and New Zealand Flux Research and Monitoring, hdl:102.100.100/14234, CSIRO, Dickson, Australia, 2013b.

Bosilovich, M. G., Chen, J., Robertson, F. R., and Adler, R. F.: Evaluation of global precipitation in reanalyses, J. Appl. Meteorol. Clim., 47, 2279-2299, 2008.

Coenders-Gerrits, A. M. J., van der Ent, R. J., Bogaard, T. A., Wang-Erlandsson, L., Hrachowitz, M., and Savenije, H. H. G.: Uncertainties in transpiration estimates, Nature, 506, doi:10.1038/nature12925, 2014.

Decker, M., Pitman, A., and Evans, J. P.: Groundwater constraints on simulated transpiration variability over Southeastern Australian forests, J. Hydrometeorol., 14, 543-559, 2013.

Decker, M., Pitman, A., and Evans, J. P.: Applying scaled vegetation greenness metrics to constrain simulated transpiration anomalies: a study over Australia, J. Hydrometeorol., 15, 1607-1623, 2014.

Dirmeyer, P. A., Gao, X., Zhao, M., Guo, Z., Oki, T., and Hanasaki, N.: GSWP-2: multimodel analysis and implications for our perception of the land surface, B. Am. Meteorol. Soc., 87, 13811397, doi:10.1175/BAMS-87-10-1381, 2006. 
Draper, C. S., Walker, J. P., Steinle, P. J., de Jeu, R. A. M., and Holmes, T. R. H.: An evaluation of AMSR-E derived soil moisture over Australia, Remote Sens. Environ., 113, 703-710, 2009.

Evans, J. P., Pitman, A. J., and Cruz, F. T.: Coupled atmospheric and land surface dynamics over southeast Australia: a review, analysis and identification of future research priorities, Int. J. Climatol., 31, 1758-1772, doi:10.1002/joc.2206, 2011.

Ferguson, C. R. and Wood, E. F.: Observing land-atmosphere interaction globally with satellite remote sensing, in: Proc. Earth Observation and Water Cycle Science Symp., Frascati, Italy, edited by: Lacoste, H., ESA Publications Division, European Space Agency, Noordwijk, The Netherlands, 8 pp., 2009.

Ferguson, C. R., Wood, E. F., and Vinukollu, R. K.: A global intercomparison of modeled and observed land-atmosphere coupling, J. Hydrometeorol., 13, 749-784, doi:10.1175/JHM-D-110119.1, 2012.

Gentine, P., Entekhabi, D., and Polcher, J.: The diurnal behavior of evaporative fraction in the soil-vegetation-atmospheric boundary layer continuum, J. Hydrometeorol., 12, 1530-1546, 2011.

Gentine, P., Ferguson, C. R., and Holtslag, A. A. M.: Diagnosing evaporative fraction over land from boundarylayer clouds, J. Geophys. Res.-Atmos., 118, 8185-8196, doi:10.1002/jgrd.50416, 2013a.

Gentine, P., Holtslag, A. A. M., D’Andrea, F., and Ek, M.: Surface and Atmospheric Controls on the Onset of Moist Convection over Land, J. Hydrometeorol., 14, 1443-1462, 2013 b.

Guo, Z., Dirmeyer, P. A., Koster, R. D., Bonan, G., Chan, E., Cox, P., Gordon, C. T., Kanae, S., Kowalczyk, E., Lawrence, D., Liu, P., Lu, C.-H., Malyshev, S., Mcavaney, B., Mcgregor, J. L., Mitchell, K., Mocko, D., Oki, T., Oleson, K. W., Pitman, A., Sud, Y. C., Taylor, C. M., Verseghy, D., Vasic, R., Xue, Y., and Yamada, T.: GLACE: the global land-atmosphere coupling experiment. Part II: Analysis, J. Hydrometeorol., 7, 611-625, doi:10.1175/JHM511.1, 2006.

Hirsch, A., Kala, J., Pitman, A. J., Carouge, C., Evans, J. P., Haverd, V., and Mocko, D.: Impact of land surface initialisation approach on sub-seasonal forecast skill: a regional analysis in the Southern Hemisphere, J. Hydrometeorol., 15, 300-319, 2014.

Huffman, G. J., Bolvin, D. T., Nelkin, E. J., Wolff, D. B., Adler, R. F., Gu, G., Hong, Y., Bowman, K. P., and Stocker, E. F.: The TRMM Multisatellite Precipitation Analysis (TMPA): quasiglobal, multiyear, combined-sensor precipitation estimates at fine scales, J. Hydrometeorol., 8, 38-55, doi:10.1175/JHM560.1, 2007.

Jiménez, C., Prigent, C., Mueller, B., Seneviratne, S. I., McCabe, M. F., Wood, E. F., Rossow, W. B., Balsamo, G., Betts, A. K., Dirmeyer, P. A., Fisher, J. B., Jung, M., Kanamitsu, M., Reichle, R. H., Reichstein, M., Rodell, M., Sheffield, J., Tu, K., and Wang, K.: Global intercomparison of 12 land surface heat flux estimates, J. Geophys. Res., 116, D02102, doi:10.1029/2010JD014545, 2011.

Jones, D. A., Wang, W., and Fawcett, R.: High-quality spatial climate data-sets for Australia, J. Aust. Meteor. Oceanogr., 58, 233248, 2009.

Jung, M., Reichstein, M., Ciais, P., Seneviratne, S. I., Sheffield, J., Goulden, M. L., Bonan, G., Cescatti, A., Chen, J., de Jeu, R., Dolman, A. J., Eugster, W., Gerten, D., Gianelle, D., Gobron, N., Heinke, J., Kimball, J., Law, B. E., Montagnani, L., Mu, Q., Mueller, B., Oleson, K., Papale, D., Richard- son, A. D., Roupsard, O., Running, S., Tomelleri, E., Viovy, N., Weber, U., Williams, C., Wood, E., Zaehle, S., and Zhang, K.: Recent decline in the global land evapotranspiration trend due to limited moisture supply, Nature, 467, 951-954, doi:10.1038/nature09396, 2010.

Koster, R. D. and Suarez, M. J.: Impact of land surface initialization on seasonal precipitation and temperature prediction, J. Hydrometeorol., 4, 408-423, 2003.

Koster, R. D., Suarez, M. J., Higgins, R. W., and Van den Dool, H. M.: Observational evidence that soil moisture variations affect precipitation, Geophys. Res. Lett., 30, 1241, doi:10.1029/2002GL016571, 2003.

Koster, R. D., Suarez, M. J., and Heiser, M.: Variance and predictability of precipitation at seasonal-to-interannual timescales, J. Hydrometeorol., 1, 26-46, 2000.

Koster, R. D., Guo, Z., Dirmeyer, P. A., Bonan, G., Chan, E., Cox, P., Davies, H., Gordon, C. T., Kanae, S., Kowalczyk, E., Lawrence, D., Liu, P., Lu, C.-H., Malyshev, S., Mcavaney, B., Mitchell, K., Mocko, D., Oki, T., Oleson, K. W., Pitman, A., Sud, Y. C., Taylor, C. M., Verseghy, D., Vasic, R., Xue, Y., and Yamada, T.: GLACE: the global land-atmosphere coupling experiment, Part I: Overview, J. Hydrometeorol., 7, 590-610, 2006.

Koster, R. D., Z., Guo, R., Yang, P. A., Dirmeyer, K., Mitchell, and Puma, M. J.: On the Nature of Soil Moisture in Land Surface Models, J. Climate, 22, 4322-4335, 2009.

Koster, R. D., Mahanama, S. P. P., Yamada, T. J., Balsamo, Gianpaolo, Berg, A. A., Boisserie, M., Dirmeyer, P. A., Doblas-Reyes, F. J., Drewitt, G., Gordon, C. T., Guo, Z., Jeong, J.-H., Lee, W.-S., Li, Z., Luo, L., Malyshev, S., Merryfield, W. J., Seneviratne, S. I., Stanelle, T., van den Hurk, B. J. J. M., Vitart, F., and Wood, E. F.: The second phase of the global land-atmosphere coupling experiment: soil moisture contributions to subseasonal forecast skill, J. Hydrometeorol., 12, 805-822, doi:10.1175/2011JHM1365.1, 2011.

Lee, J.-E., Lintner, B., Neelin, J. D., Jiang, X., Gentine, P., Boyce, C. K., Fisher, J. B., Perron, J. T., Kubar, T. L., Lee, J., and Worden, J. R.: Reduction of tropical land region precipitation variability via transpiration, Geophys. Res. Lett., 39, L19704, doi:10.1029/2012GL053417, 2012.

Lintner, B. R. and Neelin, J. D.: Soil moisture impacts on convective margins, J. Hydrometeorol., 10, 1026-1039, 2009.

Lintner, B. R., Gentine, P., Findell, K. L., D'Andrea, F., Sobel, A. H., and Salvucci, G. D.: An idealized prototype for large-scale land-atmosphere coupling, J. Climate, 26, 2379-2389, 2013.

Liu, Y. Y., van Dijk, A. I. J. M., De Jeu, R. A. M., and Holmes, T. R. H.: An analysis of spatiotemporal variations of soil and vegetation moisture from a 29-year satellite-derived data set over mainland Australia, Water Resour. Res., 45, W07405, doi:10.1029/2008WR007187, 2009.

Meng, X. H., Evans, J. P., and McCabe, M. F.: The impact of observed vegetation changes on land-atmosphere feedbacks during drought, J. Hydrometeorol., 15, 759-776, doi:10.1175/JHM-D13-0130.1, 2014a.

Meng, X. H., Evans, J. P., and McCabe, M. F.: The influence of inter-annually varying albedo on regional climate and drought, Clim. Dynam., 42, 787-803, doi:10.1007/s00382-013-1790-0, 2014b.

Miralles, D. G., De Jeu, R. A. M., Gash, J. H., Holmes, T. R. H., and Dolman, A. J.: Magnitude and variability of land evaporation and 
its components at the global scale, Hydrol. Earth Syst. Sci., 15, 967-981, doi:10.5194/hess-15-967-2011, 2011a.

Miralles, D. G., Holmes, T. R. H., De Jeu, R. A. M., Gash, J. H., Meesters, A. G. C. A., and Dolman, A. J.: Global land-surface evaporation estimated from satellite-based observations, Hydrol. Earth Syst. Sci., 15, 453-469, doi:10.5194/hess-15-453-2011, $2011 b$.

Mu, Q., Heinsch, F. A., Zhao, M., and Running, S. W.: Development of a global evapotranspiration algorithm based on MODIS and global meteorology data, Remote Sens. Environ., 111, 519-536, doi:10.1016/j.rse.2007.04.015, 2007.

$\mathrm{Mu}$, Q., Zhao, M., and Running, S. W.: Improvements to a MODIS global terrestrial evapotranspiration algorithm, Remote Sens. Environ., 115, 1781-1800, doi:10.1016/j.rse.2011.02.019, 2011.

Njoku, E. G., Jackson, T. J., Lakshmi, V., Chan, T. K., and Nghiem, S. V.: Soil moisture retrieval from AMSR-E, IEEE T. Geosci. Remote, 41, 215-229, doi:10.1109/TGRS.2002.808243, 2003.

Oleson, K. W., Lawrence, D. M., Bonan, G. B., Flanner, M. G., Kluzek, E., Lawrence, P. J., Levis, S., Swenson, S. C., Thornton, P. E., Dai, A., Decker, M., Dickinson, R., Feddema, J., Heald, C. L., Hoffman, F., Lamarque, J.-F., Mahowald, N., Niu, G.-Y., Qian, T., Randerson, J., Running, S., Sakaguchi, K., Slater, A., Stöckli, R., Wang, A., Yang, Z.-L., Zeng, X., and Zeng, X.: Technical Description of Version 4.0 of the Community Land Model (CLM), National Center for Atmospheric Research (NCAR), Boulder, Colorado, doi:10.5065/D6FB50WZ, 2010.

Pielke, R. A., Pitman, A., Niyogi, D., Mahmood, R., McAlpine, C., Hossain, F., Goldewijk, K. K., Nair, U., Betts, R., Fall, S., Reichstein, M., Kabat, P., and de Noblet, N.: Land use/land cover changes and climate: modeling analysis and observational evidence, WIREs Clim. Change, 2, 828-850, doi:10.1002/wcc.144, 2011.

Pitman, A. J.: The evolution of, and revolution in, land surface schemes designed for climate models, Int. J. Climatol., 23, 479510, doi:10.1002/joc.893, 2003.

Press, W. H., Flannery, B. P., Teukolsky, S. A., and Vetterling, W. T.: Nonparametric or rank correlation, numerical recipes, in: C: the Art of Scientific Computing, 2nd Edn., edited by: Cowles, L. and Harvey, A., Cambridge University Press, UK, 639-644, 1992.
Qian, T., Dai, A., Trenberth, K. E., and Oleson, K. W.: Simulation of global land surface conditions from 1948 to 2004, Part I: Forcing data and evaluations, J. Hydrometeorol., 7, 953-975, doi:10.1175/JHM540.1, 2006.

Rodell, M., Houser, P. R., Jambor, U., Gottschalck, J., Mitchell, K., Meng, C.-J., Arsenault, K., Cosgrove, B., Radakovich, J., Bosilovich, M., Entin, J. K., Walker, J. P., Lohmann, D., and Toll, D.: The global land data assimilation system, B. Am. Meteorol. Soc., 85, 381-394, doi:10.1175/BAMS-85-3-381, 2004.

Santanello, J. A., Peters-Lidard, C. D., and Kumar, S. V.: Diagnosing the sensitivity of local land-atmosphere coupling via the soil moisture-boundary layer interaction, J. Hydrometeorol., 12, 766-786, doi:10.1175/JHM-D-10-05014.1, 2011.

Schenk, H. J. and Jackson, R. B.: The Global Biogeography of Roots, Ecol. Monogr., 73, 311-328, 2002.

Schlesinger, W. H. and Jasechko, S.: Transpiration in the global water cycle, Agr. Forest Meteorol., 189-190, 115-117, doi:10.1016/j.agrformet.2014.01.011, 2014.

Seneviratne, S. I., Corti, T., Davin, E. L., Hirschi, M., Jaeger, E. B., Lehner, I., Orlowsky, B., and Teuling, A. J.: Investigating soil moisture-climate interactions in a changing climate: a review, Earth-Sci. Rev., 99, 125-161, doi:10.1016/j.earscirev.2010.02.004, 2010.

Taylor, C. M. and Ellis, R. J.: Satellite detection of soil moisture impacts on convection at the mesoscale, Geophys. Res. Lett., 33, L03404, doi:10.1029/2005GL025252, 2006.

Westra, D., Steeneveld, G. J., and Holstag, A. A. M.: Some observational evidence for dry soils supporting enhanced relative humidity at the convective boundary layer top, J. Hydrometeorol., 13, 1347-1358, 2012.

Williams, J. L. and Maxwell, R. M.: Propagating subsurface uncertainty to the atmosphere using fully coupled stochastic simulations, J. Hydrometeorol., 12, 690-701, doi:10.1175/2011JHM1363.1, 2011.

Zhang, J., Wang, W.-C., and Wei, J.: Assessing land-atmosphere coupling using soil moisture from the global land data assimilation system and observational precipitation, J. Geophys. Res., 113, D17119, doi:10.1029/2008JD009807, 2008. 